\title{
Descoberta e redescoberta de um espólio itinerante
}

\author{
FORNARI, Maria Cristina. Uma \\ Aventura de mais de um Século. A \\ História das Edições de Nietzsche. \\ Trad. Maria Elisa Bifano. São \\ Paulo: Editora Unifesp, 2019.
}

Eduardo Nasser*

O mais novo título da série Recepção, parte da coleção Sendas \& Veredas, Uma Aventura de mais de um Século. A História das Edições de Nietzsche, de Maria Cristina Fornari, renomada pesquisadora e professora da Universidade de Salento, tem por objeto o destino do espólio de Nietzsche, "de suas obras e cartas, da biblioteca" e "em especial do que ficou por fazer" (p. 11). Longe de ser um enfadonho trabalho de arquivista, consiste numa trama vibrante, margeada por um meticuloso empreendimento investigativo. Fornari salienta que

\footnotetext{
* Professor Pesquisador da Alexander von Humboldt-Stiftung na Albert-Ludwigs-Universität Freiburg, Freiburg, Alemanha. Bolsista CAPES

ORCID: https://orcid.org/0000-0002-8415-7149

Correio eletrônico: eduardo.nasser@philosophie.uni-freiburg.de
} 
Nasser, E.

quis contar essa história aos moldes de um romance, sem renunciar ao "rigor científico" (p. 13)¹. Essa admirável combinação de elementos é engrandecida pela competente tradução de Maria Elisa Bifano, bem como pela preciosa revisão técnica de Scarlett Marton.

O cerne da primeira parte do livro são os delitos editoriais cometidos por Elisabeth Förster-Nietzsche e seus efeitos desastrosos. Somos levados a ver, com uma impressionante riqueza de detalhes, de que forma a soeur terrible, dominada por desejos sórdidos de fama e fortuna, e cercada por pávidos cúmplices e bajuladores, se apodera da herança espiritual de Nietzsche a fim de criar um novo objeto de culto, não importando os onerosos custos morais e científicos, incluindo ocultação, falsificação e até mesmo destruição de manuscritos, cartas e livros da biblioteca pessoal.

Essa parte embaraçosa da história começa logo após o colapso de Nietzsche em Turim, quando as conversações mais ponderadas e respeitosas mantidas por Franz Overbeck e Heinrich Köselitz sobre os rumos das últimas obras do amigo e mestre, prestes a serem publicadas por Naumann, são rapidamente sucedidas pelo cenário mais caótico criado por Elisabeth. Recém-regressada da experiência malograda no Paraguai e ávida por algum tipo de compensação, ela define como a sua nova meta de vida ser a única representante de Nietzsche. Almejava ser a biógrafa, organizadora das obras completas e, até mesmo, tutora do irmão alienado, que seria levado a Weimar para ser usado como um acessório extravagante dos Arquivos Nietzsche. A última tarefa não é de imediato levada a bom termo devido à resistência colocada por Franziska, a mãe protetora que mantém o filho sob a sua custódia em Naumburg até 1897; mas Elisabeth tem melhor sorte nos outros intentos.

Após assumir o comando da organização das obras completas, destituindo um impotente Köselitz, e se ocupar mais firmemente de

1 Diferencia-se, assim, de outros empreendimentos similares, tais como os realizados por Hoffmann. Cf. Hoffmann, 1991, p. 3 - 131; 1993, p. 25 - 94. Saliente-se, ainda, que a obra de Fornari traz um aporte mais atualizado, como era de esperar.

196 | Cad. Nietzsche, Guarulhos/Porto Seguro, v.41, n.1, p. 195-202, janeiro/abril, 2020. 
sua "biografia hagiográfica", Elisabeth dá início à reunião de todo o material que Nietzsche escreveu - "cada linha era um tesouro em potencial" (p. 33) -, incluindo as missivas, tanto dele quanto dos destinatários, um tipo de atividade extenuante que dá uma ideia de sua obstinação. Todavia, Fornari deixa muito claro que esse afinco jamais foi pautado por motivações genuinamente científicas. O real intuito de Elisabeth era se beneficiar do estrondoso impacto cultural que o irmão estava provocando em vários segmentos da sociedade alemã. Dirige toda a sua energia para a elaboração da imagem de Nietzsche, um propósito estritamente propagandístico que termina por involucrar a organização das obras completas ("minha missão nas próximas décadas será a de enraizar fundo no coração do público a imagem de Nietzsche, essa figura iluminada. É isso o que me motiva a fazer as minhas publicações", p. 36). Essa era uma finalidade inegociável. E qualquer um dos inúmeros colaboradores de Elisabeth (como Koegel, Steiner, Seidl, os irmãos Horneffer, Weiss, etc., além, naturalmente, do inconstante Köselitz, todos cautelosamente tematizados por Fornari) que colocasse objeções, ou que não estivesse suficientemente comprometido - o que significava, no geral, incapacidade em conciliar o tempo de trabalho com os manuscritos, obrigatoriamente vagaroso, com a velocidade da máquina de propaganda, tolerante com toda sorte de infidelidade filológica -, tinha invariavelmente o mesmo destino: o afastamento.

Um momento particularmente didático a esse respeito, evocado de forma estratégica no livro, é a reação de Elisabeth a um fato inusitado ocorrido em Sils-Maria, quando Nietzsche, interessado na pintura de natureza morta que uma jovem dama inglesa realizava, a aconselha a contrastar o belo com algo feio, um sapo (ou uma rã?), que ele mesmo se encarrega de capturar. Indignada com o relato, Elisabeth publica um artigo na revista Die Zukunft em que acusa o divulgador da historieta, Durisch, de transmitir uma imagem difamatória do irmão enquanto um tipo de delinquente que se diverte ao "assustar senhoras discretas e debochar delas" (p. 43). Contudo, 
Nasser, E.

o fato é que Elisabeth estava inteirada da veracidade do relato, visto que era de seu conhecimento a carta enviada pela mãe da pintora, Emily Flinn, para Franziska, na qual confirma o ocorrido. Portanto, como diz Bernoulli, guardião da correspondência de Overbeck, num trecho oportunamente citado por Fornari, "talvez justamente este pequeno e insignificante exemplo seja útil para abrir os olhos de muitas pessoas indulgentes demais a respeito do sistema operacional que era responsável pela produção das "lendas Nietzsche" (p. 45).

A anedota funciona como um tipo de preparação para o leitor ser conduzido ao cenário mais obsceno de adulterações e violações praticadas por Elisabeth. A lista causa perplexidade:

- Destruição e falsificação, integral ou parcial, das cartas de Lou, Rée, Franziska, Overbeck, Bernhard Förster e "uma boa parte de suas próprias, dentre as quais, sem exceções aquelas dos anos de 1882-1884" (p. 51);

- Quando da publicação do oitavo volume da Grossoktavausgabe (GOA), alteração do título de $O$ Anticristo, que teve também "quatro passagens censuradas" (p. 57);

- Constante adiamento da publicação de Ecce Homo, cujo conteúdo poderia ser prejudicial à "imagem de Nietzsche" e, ao lado de Köselitz, e mesmo de Franziska, falsificações dessa obra, "não de poucas e pequenas passagens que as edições seguintes poderiam nos devolver, mas de textos importantes, não se sabe quais, que foram ocultos e propositalmente destruídos" (p. 93);

- E, evidentemente, a fabricação de a Vontade de Potência, seguramente um dos incidentes mais conhecidos pelos nietzschianos, quando, por meio de uma perversa e inesperada parceria com Köselitz, agora Peter Gast, e sob a alegação de ter descoberto a obra perdida do irmão em prosa, que conferiria fechamento ao projeto da Transvaloração de todos 
os valores, agrupa aleatoriamente anotações de Nietzsche, mais diretamente na segunda edição, de 1906, "sozinha e sem ajuda científica" (p. 78).

Mas ao sair praticamente ilesa após executar tão graves infrações, sendo regularmente aclamada - recebe um doutorado honoris causa da Universidade de Iena, quatro indicações para o Nobel de literatura, é afagada por personalidades artísticas, acadêmicas e políticas, incluindo Hitler, com quem frequentemente se entretém -, é provável que Elisabeth tenha sido vítima do excesso de autoconfiança, tornando-se descuidada. Num dos momentos mais interessantes do livro, Fornari nos mostra de que modo a edição histórico-crítica (BAW), projeto editorial entabulado no começo da década de 1930, cujo intuito era reparar a reputação cada vez mais deteriorada das obras organizadas nos Arquivos, precipita o fim da farsa. Não obstante os membros da comissão científica da nova edição, Joachim Mette e Karl Schlechta, trabalharem nas anotações de Nietzsche com o consentimento de Elisabeth, em segredo, "com a discrição e aquiescência externa de um grupo de conspiradores" (p. 112), planejam desfazer as manipulações cometidas.

Apesar de terem sido publicados somente cinco volumes das obras (quatro das cartas) dos quarenta previstos, a edição BAW pode ser vista como um sinal de que o futuro será mais generoso com o espólio nietzschiano, afinal, foi “o primeiro exemplo de um trabalho científico durante a longa história dos Arquivos Nietzsche" (p. 115). Esse presságio é confirmado com o surgimento da edição organizada por Giorgio Colli e Mazzino Montinari, foco da segunda parte do livro $^{2}$. Possuidores de uma jovial energia, tenacidade e zelo filológico, realizam a recuperação de documentos corrompidos, de transcrições e datações inadequadas, além de divulgarem uma grande quantidade de material inédito. Existem, por certo, pontos de contato entre as

2 Cf. também: Campioni, 1992. 
Nasser, E.

diretrizes da nova iniciativa italiana com o projeto descontinuado da edição BAW, assim como com os louváveis empreendimentos alemães do pós-guerra encabeçados por Schlechta e Erich Podach, que prosseguem engajados, de diferentes formas, com a campanha desmistificadora. Mas em virtude da persistência de imperfeições técnicas nessas realizações - "as edições de Schlechta e Podach, ao lado da (suposta) boa vontade filológica mostram limites evidentes" (p. 126) -, a autora é também bastante firme, não abrindo mão de se guiar pelo indelével corte epistemológico impresso pela edição Colli-Montinari.

A edição foi gerada como que por obra do destino. Pouco depois de assinar o contrato de uma nova tradução de Nietzsche com Einaudi em 1959, Colli é alertado por Montinari, que tinha ido a Weimar em abril de 1961 para avaliar os manuscritos, acerca da necessidade de providenciar uma nova edição, porquanto "correções de texto não seriam suficiente" (p. 139). Segue-se uma cadeia de impactantes repercussões provocadas pela audaciosa decisão de assumir o desafio, todas aclaradas por Fornari: mudança de editora (Adelphi); transferência em definitivo de Montinari para Weimar no ano de 1965, onde ficaria por nove anos; e, dentre as consequências cientificamente mais prósperas, implantação de um critério confiável de ordenação dos póstumos - cronológico ao invés do temático, outrora adotado na edição GOA - e a criação de uma nova metodologia de estudo, "em uma direção histórica e anti-metafísica, filológica e não atualizadora" (p. 150). Posteriormente, graças a Giuliano Campioni, esse método serve de estímulo para a formação da escola italiana de pesquisadores, dedicada especialmente ao estudo de fontes e à preservação e catalogação da biblioteca de Nietzsche.

Em todo o caso, as inovações contidas na edição crítica enfrentam uma recepção relutante, ao contrário do que se poderia supor. A começar pela prenunciada indisposição de nomes importantes da pesquisa Nietzsche, cujas monografias eram amplamente respaldadas pela Vontade de Potência, como Karl Löwith. É por esse motivo que 
Colli e Montinari participam do célebre Colóquio de Royaumont munidos de um "plano de batalha" (p. 140). Mas os inconvenientes não estão circunscritos à época. No momento mais desconcertante do livro - mais até do que a exposição do caso Elisabeth -, Fornari nos coloca em contato com recentes ataques feitos por nomes conhecidos da comunidade filosófica, como Maurizio Ferraris e Domenico Losurdo. Convencidos de que a edição crítica não provoca uma significativa alteração no conteúdo de a Vontade de Potência, entendem que os resultados divulgados seriam de teor dissimulatório e que Colli e Montinari continuam vinculados ao antigo plano de canonização de Nietzsche, ainda que com outra roupagem ideológica. É possível que esse argumento falacioso tenha sido benéfico para o mercado editorial, haja vista a quantidade de reimpressões de a Vontade de Potência em vários países nas últimas décadas, inclusive no Brasil.

Embora o fantasma de Elisabeth ainda assombre, Fornari conclui o livro trazendo um panorama alentador. Nesse momento, discorre sobre os herdeiros de Colli e Montinari que em nossa atualidade promovem avanços em direção a um tratamento mais criterioso dos escritos de Nietzsche. Trata-se do Nietzsche Source, um desdobramento do HyperNietzsche. O projeto, dirigido por Paolo D'Torio, disponibiliza “a todos os nietzschianos, a Digitale Kritische Gesamtausgabe (ou seja, a versão digital da edição Colli-Montinari das obras e das cartas), a Digitale Faksimile Gesamtausgabe (reprodução em fac-símile, embora ainda incompleta, do espólio de Nietzsche: primeiras edições das obras, manuscritos, cartas e documentos biográficos)", além da inclusão, a ser em breve concluída, "dos volumes da biblioteca pessoal completamente digitalizados e acrescidos de comentários" (p. 183). A edição digitalizada vem também acompanhada por uma grande quantidade de correções da edição Colli-Montinari, melhorias que não passam despercebidas aos olhos do pesquisador experimentado ${ }^{3}$.

3 A esse respeito, $c f$. Paolo D'Iorio, Paolo, 2010, pp. 164-74. 
Nasser, E.

Nietzsche dizia que a obra, quando descolada do criador, passa a gozar de uma vida própria, algo que, num certo sentido, ele reafirma ao se voltar para a sua produção mesma: uma coisa sou eu, outra são meus escritos. O livro de Fornari revela que, malgrado essa apreciação, o espólio de Nietzsche conhece uma vida similar à do autor: atribulada, incerta, itinerante, enfim, aventurosa. Resta agora saber se terá um desfecho menos dramático.

\section{Referências}

CAMPIONI, G. Leggere Nietzsche. Alle origini dell'edizione critica Colli-Montinari. Con lettere e testi inediti. Pisa: ETS, 1992.

D'IORIO, Paolo. "The Digital Critical Edition of the Works and Letters of Nietzsche" in: The Journal of Nietzsche Studies, 40, 2010, pp. 164-74.

FORNARI, Maria Cristina. Uma Aventura de mais de um Século. A História das Edições de Nietzsche. Trad. Maria Elisa Bifano. São Paulo: Editora Unifesp, 2019.

HOFFMAnN, David Marc. Zur Geschichte des Nietzsche-Archivs. Chronik, Studien und Dokumente. Berlin/New York: Walter de Gruyter, 1991.

. Das "Basler Nietzsche-Archiv". Katalog der Ausstellung. Basel: Universitätsbibliothek Basel, 1993.

Enviada: 22/02/2020

Aceita: 14/03/2020 